\title{
Specific Antitumor Effects of Tumor Vaccine Produced by Electrofusion between Osteosarcoma Cell Line and Dendritic Cells in Rats
}

\author{
Zhe Yu, Qingyu Fan, Bao’an Ma, Yong Zhou, Minghua Zhang, Xiuchun Qiu \\ Center of Orthopedic Surgery, Orthopedics Oncology Institute of Chinese PLA, Tangdu Hospital, Fourth Military Medical \\ University, Xi'an 710038, Shaanxi, China
}

\begin{abstract}
Background: Dendritic cells (DCs) are the strongest antigen presenting cells (APCs). They can present antigen to T lymphocytes in vivo and in vitro, and induce cytotoxic T lymphocyte (CTL) reactions. This study was designed to investigate the immunologic potency and antitumor effecs of tumor vaccine produced by electrofusion between rat osteosarcoma cells and DCs.

Methods: DCs obtained from rat bone marrow were propagated in vitro under the condition of rGM-CSF, rIL-4 and rTNF- $\alpha$ and were purified by monoclonal antibody OX62 and magnetic beads. Then the UMR-106 cell line was fused with DCs to produce the tumor vaccine and the specific antitumor effects of the tumor vaccine were observed.

Results: A comparison of electrofusion products generated with allogeneic versus syngeneic DCs was conducted. $70 \%$ of the rats immunized with allogeneic electrofused cells were typically able to reject tumor challenge and remained tumorfree, while $50 \%$ in the syngeneic group. Vaccinated survivors developed long immunological memory. 7 weeks after the second challenge, all the immunized rats survived. The therapeutic potential of this type of approach was suggested by the ability of UMR106-DC electrofusion products to induce tumor rejection in a substantial percentage of hosts (60\%) bearing pre-established tumor cells.

Interpretations: Treatment with electrofused tumor cells and allogeneic DCs might be capable of inducing a potent antitumor response and could conceivably be applied to a wide range of cancer indications for which tumor-associated antigens have not been identified.
\end{abstract}

Key Words: Dendritic cell, osteosarcoma, tumor vaccine

(Received June 21, 2005; Accepted September 6, 2005)

\section{Introduction}

Although the immune system is there to protect the host from infection, what damps the popular imagination is its potential to recognise and destroy cancer. The immune system can generate potent cytotoxicity (e.g. transplant rejection), but this mechanism can not be fully harnessed for therapeutic benefit in patients with cancer. As it is known that an ever-increasing array of tumour antigens is in existence. The challenge lies in generating a sufficiently potent response towards the tumour antigens. Dendritic cells (DCs) are the best professional antigen-presenting cells (APCs) and they have been used extensively in this context because they can increase the surface expression of major histocompatibility complex (MHC) antigens of class I and class II, and co-stimulatory molecules (required for efficient presentation of peptides and stimulation of $\mathrm{T}$ cells) ${ }^{1}$ and can synthesize a variety of immunologically important cytokines such as IL-1, TNF- $\alpha$, and IL-12. Results from numerous studies have indicated that DCs pulsed with defined tumorassociated peptides ${ }^{2,3)}$, tumor lysate $e^{4,5)}$, apoptotic or necrotic tumor cells ${ }^{6}$, just like DCs genetically modified to express tumor-associated antigens using viral vectors ${ }^{7,8)}$ or tumor $\mathrm{RNA}^{9-11)}$, are all capable of eliciting a tumorspecific cytotoxic T-cell response. To further develop effective DC-based strategies, fusion of DCs with tumor cells is particularly attractive. It offers the theoretical advantage of ensuring a broad and continuous source of unaltered tumor antigens as well as superior antigen presenting functionality of DCs. Several studies have shown that fusion cells were functionally active in stimulating both $\mathrm{CD}^{+}$and $\mathrm{CD}^{+} \mathrm{T}$ cells and eradicating established tumor metastases ${ }^{12-14)}$. The fusion hybrids combine the antigens from the tumor cells with the antigen-presenting and co-stimulatory properties of DCs thus allowing for effective presentation of the full complement of potential antigens within the tumor, both known and unknown. However, the traditional fusion method using polyethylene glycol (PEG) is often plagued by its too widely ranging efficiencies, toxicity, poor reproducibility, and vary- 
ing susceptibilities among individual tumor cell partners. We have recently described an alternative means of generating DC-tumor hybrids by exposing cells to electric fields. The success of fusion has unequivocally been verified by a number of analyses including FACS, cytospin, confocal immunofluorescence, and DNA content. The efficiency of electrofusion is usually ten to hundreds times higher than the chemical methods ${ }^{15,16)}$.

Osteosarcomas are the prominent primary bone cancers in humans, excluding hemopoietic malignancies. They mainly affect children and adolescents and are usually highly aggressive and eventually lethal. The current grading and staging systems of osteosarcoma are based on a combination of clinicopathologic features, namely, the histological appearance of the tumor and its local and/or disseminated spread. However, an unequivocal discrimination of osteosarcomas into categories with distinct clinical behavior and prognosis has not yet been achieved, largely due to the protean morphologic presentations of these tumors. Combinations of adjuvant chemotherapy and surgery have resulted in improved survival rates ${ }^{17)}$. In an attempt to individualize the therapeutic interventions offered to osteosarcoma patients, immunotherapy might make a contribution to the prevention and cure. Although clinical trials have already been conducted on several malignant tumors, there is actually little or no information available on the performance and nature of the response elicited by electrofused DC-tumor cells in animal osteosarcoma models. In this study, an electrofusion protocol was developed and optimized and the activity of the electrofusion products generated was tested in tumor models possessing different growth and immunogenic properties. The level of efficacy and longevity of the immune response induced by vaccination were investigated.

\section{Materials and methods}

\subsection{Rats and Cell lines}

Male SD and Wistar rats, 4 to 6 weeks old, were purchased from the laboratory animal research centre of Fourth Military Medical University. The rats were maintained in microisolator cages under specific pathogenfree conditions. The UMR106 osteosarcoma cell line syngeneic to SD rats was purchased from the American Type Culture Collection (ATCC; Manassas, VA). The cell line was cultured in RPMI-10\% FBS (Sigma) supplemented with L-glutamine $(2 \mathrm{mM})$, penicillin (100 $\mathrm{U} / \mathrm{ml})$, and streptomycin $(100 \mu \mathrm{g} / \mathrm{ml})$ confirmed to be mycoplasma-free by routine testing.

\subsection{Dendritic cells}

Bone marrow-derived DC were generated as described previously ${ }^{18)}$ with modifications. Briefly, bone marrow was flushed from femurs and tibias and cells were depleted of erythrocytes with lysis buffer. The cells were washed and cultured overnight in culture medium, consisting of RPMI-10\% FBS. Non-adherent cells were harvested, resuspended in complete medium containing $1000 \mathrm{U} / \mathrm{ml}$ granulocyte-macrophage colony-stimulating factor (GM-CSF) plus $500 \mathrm{U} / \mathrm{ml}$ recombinant rat interleukin 4 (IL-4) and $1000 \mathrm{U} / \mathrm{ml}$ recombinant rat tumor necrosis factor- $\alpha$ (TNF- $\alpha$ ) (all cytokines from R\&D Systems), and cultured in 6 -well plates at $2 \times 10^{6}$ cells/ well. Fresh cytokines and medium were added on day 3. Non-adherent and loosely adherent cell clusters of proliferating DC were harvested on day 12, and resuspended in complete medium containing fresh cytokines. Cells were washed with PBS and incubated with mouse anti-rat Abs directed against OX62; MHC Class I; MHC ClassII; CD80 and CD86 (all prime antibodies from Serotec Systems) for $1 \mathrm{~h}$. on ice. After washed with PBS, the cells were incubated with fluorescein isothiocyanate (FITC) / phycoerythrin (PE)-conjugated goat antimouse IgG (PharMingen) for $30 \mathrm{~min}$. Samples were then washed, fixed with $2 \%$ paraformaldehyde, and analyzed by FACScan (Becton Dickinson).

\subsection{Scanning electron microscopy}

The DCs were attached to a plastic cover slip that had been coated with $1 \%$ poly-L-lysine in water for $15 \mathrm{~min}$. The cells were fixed with $1.2 \%$ glutaraldehyde in $0.1 \mathrm{M}$ phosphate-buffered saline (PBS), $\mathrm{pH} 7.4$, passed through an alcohol gradient, dried in a Ladd Critical Point Dryer, and coated with platinum in a Pplaron SEM Coating System. The fixed cells were examined with JEOL JSM-35 CF scanning electron microscope (SEM).

\subsection{Ttransmission electron microscopy}

For observation of DCs morphology and intracellular, cell preparation were fixed $1.5 \%$ glutaraldehyde in $0.1 \mathrm{M}$ cacodylate buffer, $\mathrm{pH} 7.4$, for 1 hour at $4^{\circ} \mathrm{C}$. The specimens were washed, treated with $1 \%$ osmium tetroxide in $0.1 \mathrm{M}$ cacodylate buffer, and passed through an alcohol gradient. They were future treated with propylene oxide and then embedded. The ultrathin sections were cut with an MT2 Sorvall ultramicrotome and examined with a JEOL-100-CX transmission electron microscope (TEM).

\subsection{Preparation of electrofusion vaccine}

DCs and cells were mixed at a 5:1 ratio and suspended in $0.3 \mathrm{M}$ glucose solution containing $0.1 \mathrm{mM} \mathrm{Ca}$ $\left(\mathrm{CH}_{3} \mathrm{COO}\right)_{2}, 0.5 \mathrm{mM} \mathrm{Mg}\left(\mathrm{CH}_{3} \mathrm{COO}\right)_{2}$, and $0.3 \%$ bovine serum albumin The $\mathrm{pH}$ of the fusion medium was adjusted to 7.2-7.4 with L-histidine (all chemicals were from Sigma Systems). After centrifugation, the cells were resuspended in the same fusion medium without bovine serum albumin. Routinely, $0.5 \mathrm{ml}$ of cell suspension containing $6 \times 10^{6}$ cells were processed using a specially designed electroporation cuvette, precoated on one side 
with paraffin wax (50 $\mu 1$ per cuvette). For electrofusion, a pulse generator (model ECM 2001, BTX Instrument, Genetronics, San Diego, CA) was used. Electrofusion involves two independent but consecutive steps. The first reaction is to bring cells in close contact by dielectrophoresis, which can be accomplished by exposing cells to an alternating (ac) electric field of relatively low strength ${ }^{19)}$. Cell fusion can then be triggered by applying a single square wave pulse to induce reversible cell membrane breakdown in the zone of membrane contact. For the current study, the optimal conditions for maximum electrofusion efficiency without substantial cell death (not lower than $70 \%$ viability by Trypan Blue staining) were found to consist of two consecutive rounds of an alignment pulse of $50 \mathrm{~V}$ for $5 \mathrm{~s}$ followed by a fusion pulse of $250 \mathrm{~V}$. The entire process was repeated a second time to maximize fusion efficiency. The fusion mixture was allowed to stand for $5 \mathrm{~min}$ before suspending in complete medium and then incubated at $37^{\circ} \mathrm{C}$ overnight. The nonadherent cells consisted of mainly DCs, and the adherent cells consisted of mainly fusion hybrids and tumor cells. The electrofusion products were purified by monoclonal antibody OX62 (a DC marker not expressed on tumor cells) sticking to the magnetic beads (Miltenyi Biotec) and then irradiated with 200 Gy with an Biological X-ray irradiator to ensure inactivation of the tumor cells and DCs. Samples from several cuvettes were pooled (before irradiation) when required to achieve the number of cells needed for the study. The irradiated pooled sample was then diluted in $0.3 \mathrm{M}$ glucose to the appropriate concentration for immunization.

\subsection{Immunization with electrofusion vaccine and tu- mor challenge}

Groups of 10 rats were immunized with doses of 1 $\times 10^{6}$ electrofused cells. Fresh irradiated electrofusion products were diluted to the appropriate concentration in $0.3 \mathrm{M}$ glucose and delivered intradermally with a 27-gauge needle in a total volume of $0.2 \mathrm{ml}$ into the SD rat's groin. Injection into the skin resulted in the formation of a raised "bubble" indicating an intradermal location, although some of the material might have been absorbed into the subcutaneous layer. In the pretreatment model, the rats were immunized twice, once on day 0 and again on day 14. The electrofusion products were prepared fresh each time. A lethal subcutaneous tumor challenge was carried out 1 week after the last immunization (on day 21). For the tumor challenge, vaccinated SD rats were injected with $1 \times 10^{7}$ UMR106 cells. In the therapeutic model, tumor cells were injected on day 0 and vaccination with electrofusion products was done on days 3,7 , and 14 .

\subsection{Statistical analysis}

All data were collected in a Microsoft Excel database

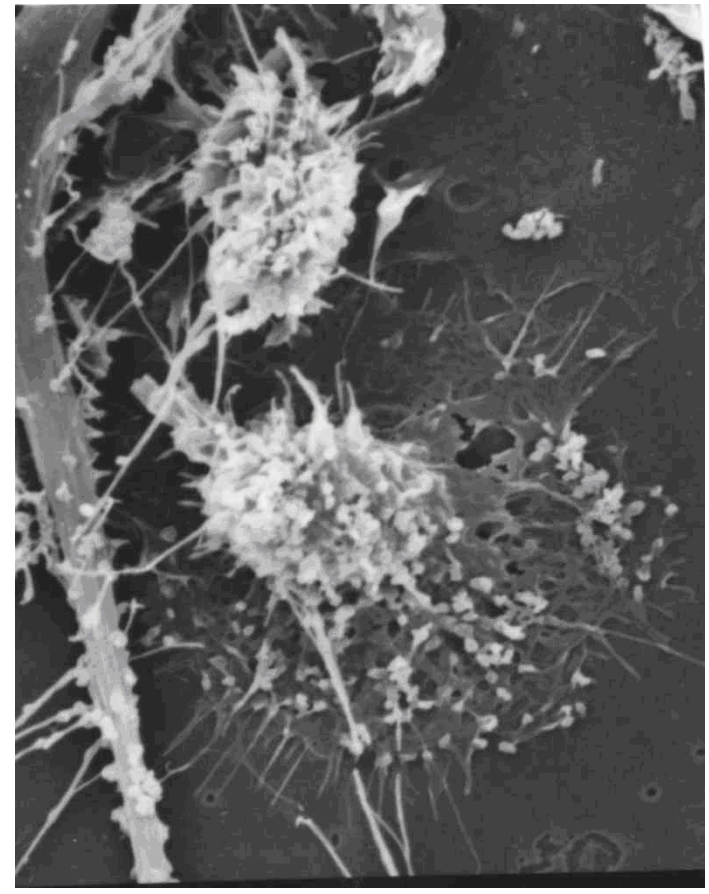

Fig. 1 DCs under scanning electron microscope DC $s$ on $d 10$ SEM $\times 3000$

on a personal computer and expressed as survival rates. Statistical significance was determined using Chi-square test. Differences were considered statistically significant with $\mathrm{P}<0.05$.

\section{Results}

\section{Identification of dendritic cells}

After culture and induction, DCs displayed typical morphology with elongated dendritic processes under both inversion microscope and electron microscope (Figs. 1 and 2). DCs expressed high level surface antigens, including OX62, 62.19\%; MHC Class I, 70.40\%; MHC Class II, 78.28\%; CD80, 55.58\%; CD86, 68.38\% (Fig. 3).

\section{Characterization of UMR106 cells fused with den- dritic cells}

Bone marrow-derived DCs were mixed with tumor cells at a 5:1 ratio and put into an electroporation cuvette. The mixture was submitted to an alignment pulse to promote cell-cell contact, and then fusion pulse was applied to induce cell membrane fusion (Fig. 4). Delivery of the alignment and fusion pulses was then repeated a second time to maximize the fusion. Then the fusion products were purified by monoclonal antibody OX62 sticking to the magnetic beads. Unfortunately, there were no perfect antibodies against rat osteosarcoma-associated antigens to label the UMR106 cells, the fusion products could not be stained for expression of both a tumor marker and a DC marker. We could only affirm the existence of 


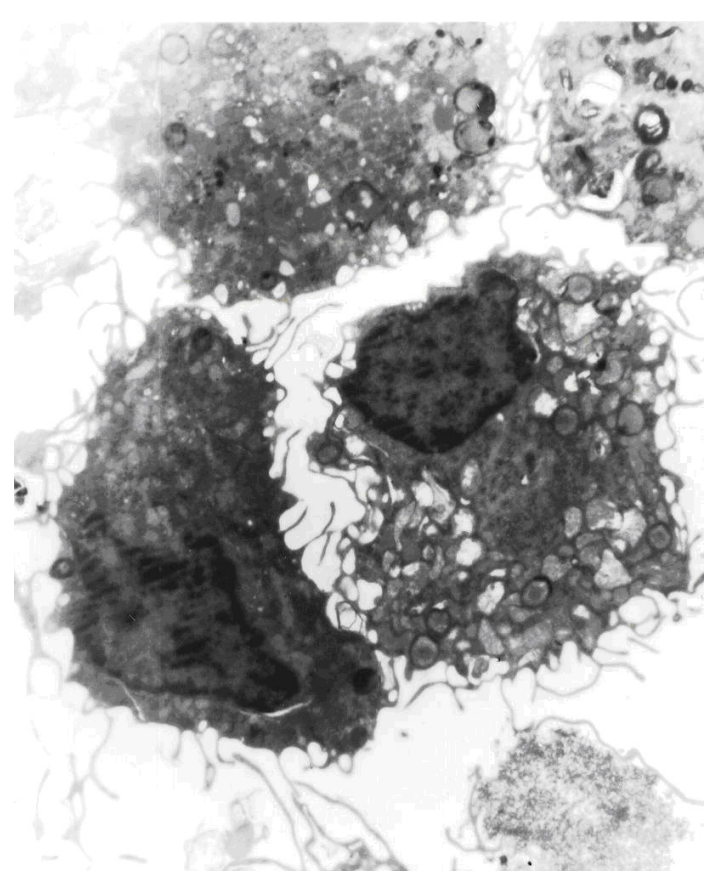

Fig. 2 DCs under transmission electron microscope DCs on d 10 TEM $\times 4000$

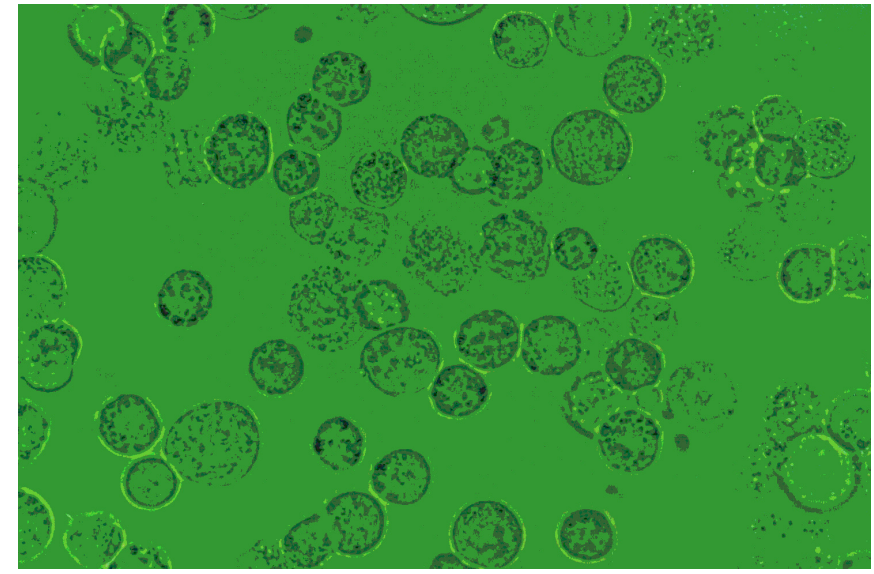

Fig. 4 Electrofusion products under inversion microscope. LM $\times 400$. The mixture was subjected to an alignment pulse to promote cell to cell contact and then to a fusion pulse to cause cell membrane fusion. The entire process was repeated a second time to maximize fusion efficiency. (30 min after the fusion pulse was administered.)
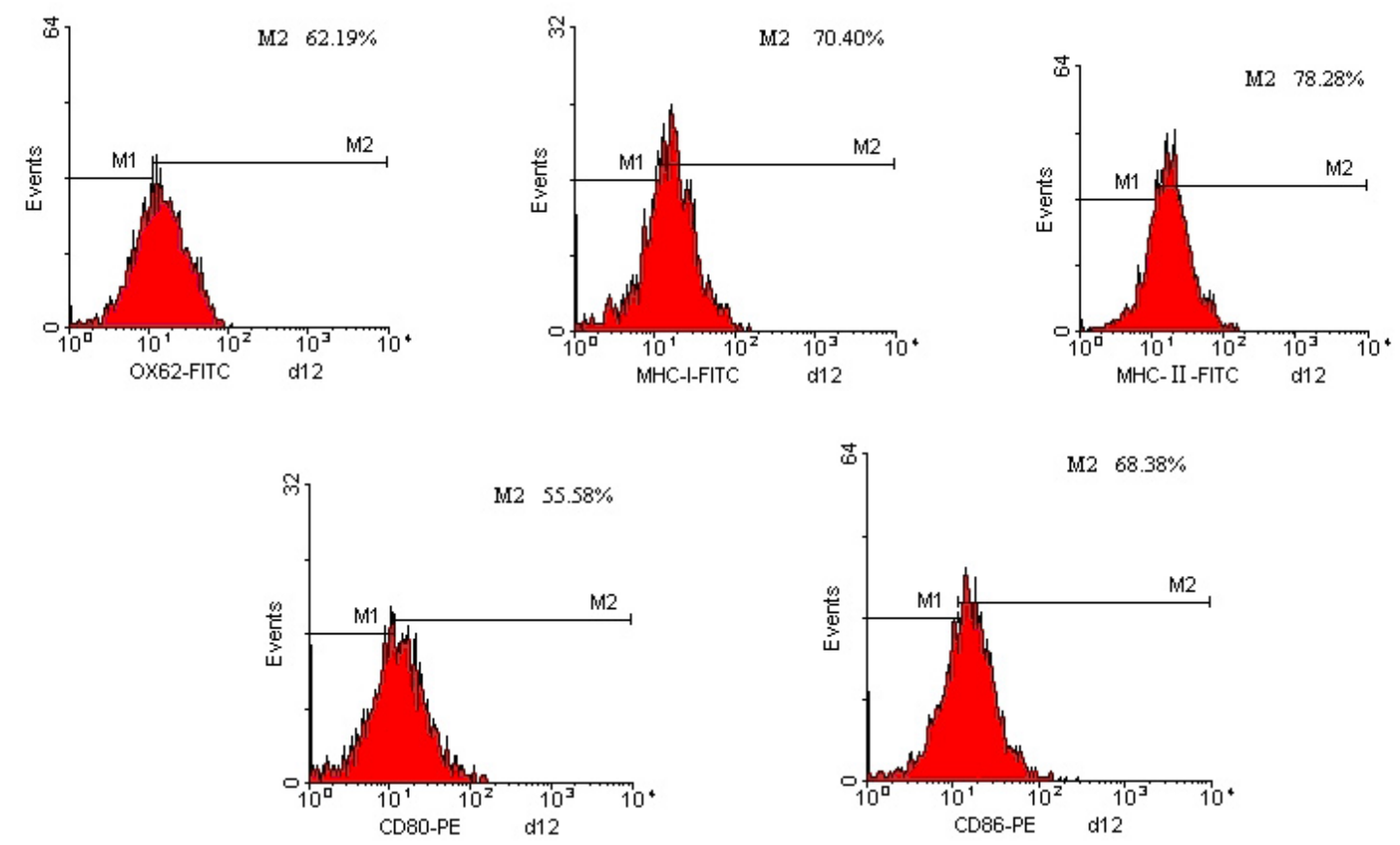

Fig. 3 FACS analysis of dendritic cells. (A) DCs stained with a FITC-labeled antibody against OX62 (62.19\%); (B) DCs stained with a FITC-labeled antibody against MHC I (70.40\%); (C) DCs stained with a FITC-labeled antibody against MHC II (78.28\%); (D) DCs stained with a PE-labeled antibody against CD80 (55.58\%); (E) DCs stained with a PE-labeled antibody against CD86 (68.38\%). 

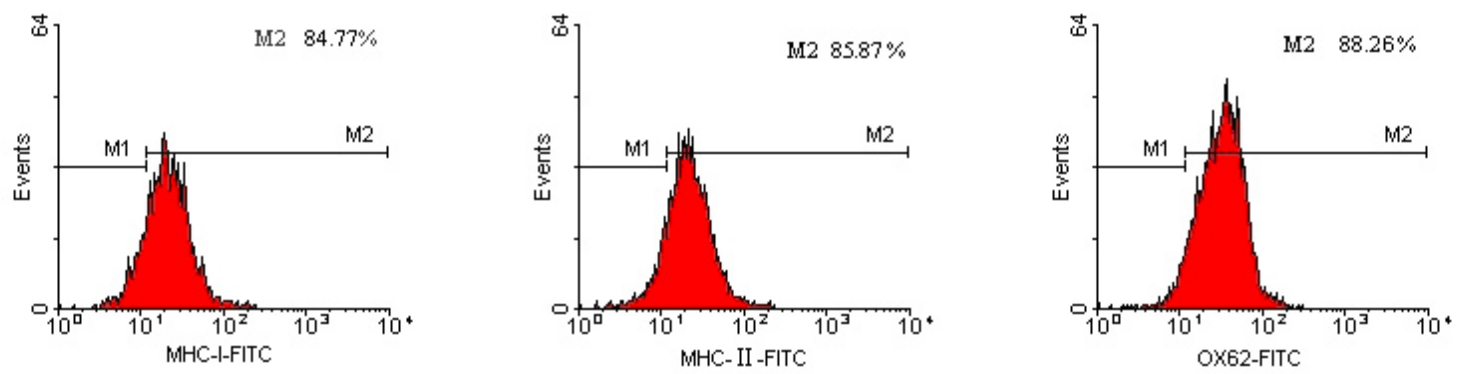

Fig. 5 FACS analysis of electrofusion products. (A) DCs stained with a FITC-labeled antibody against MHC I (84.77\%); (B) DCs stained with a FITC-labeled antibody against MHC II (85.87\%); (C) DCs stained with a FITC-labeled antibody against OX62 (88.26\%).

electrofusion products in virtue of the high expression of OX62 on adherent cells (OX62 could not be expressed on adherent osteosarcoma cells, while DCs would never be adherent), and the improvement of MHC Class I expression. FACS analysis of a purified fusion products obtained with UMR106 tumor cells and DCs is shown in Fig. 5.

\section{Immunization Against Tumor Challenge}

The ability of irradiated, electrofused tumor-DC products to induce an antitumor response and provide protection against tumor challenge was evaluated in UMR106 tumor models. In this study, rats were immunized intradermally with $1 \times 10^{6}$ electrofused cells on days 0 and 14. The intradermal route of immunization was chosen because it has been reported that mature DCs injected by this route can traffic to the draining lymph nodes.One week after the second immunization (day 21), the rats were challenged with a lethal dose of tumor cells and were then monitored for tumor growth and survival over time. The results are shown in Fig. 6. 70\% of the rats immunized with $1 \times 10^{6}$ electrofused cells were typically able to reject tumor challenge and remained tumor-free. In contrast to the results obtained with the fusion products, immunization with tumor cells that underwent the electrofusion process alone, DCs that underwent electrofusion alone, or a mixture of these two populations failed to provide the same level of antitumor protection $(\mathrm{P}<0.05)$. The difference indicated that optimal antitumor efficacy did in fact require the presence of both the tumor and the DC component during the electrofusion process and neither could be solely attributed to immunization with inactivated tumor cells.

\section{Comparison between Syngeneic and Allogeneic Dendritic Cells as Fusion Partner}

In this study, allogeneic DCs were selected as a fusion partner (for example, Wistar DCs fused to SD UMR106 tumor cells) with the aim to stimulate high frequency alloreactive $\mathrm{CD}^{+} \mathrm{T}$ cells and provide a potent source of

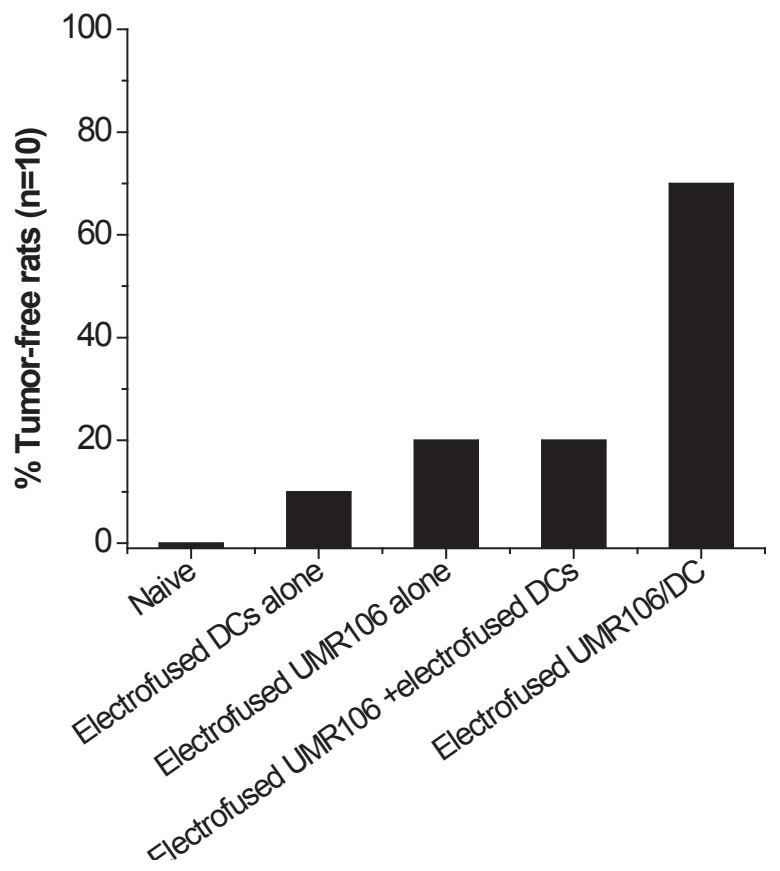

Fig. 6 Induction of antitumor protection by immunization with tumor cell-allogeneic DC fusion vaccine. In the UMR106 model, SD rats were immunized with DCs that underwent the electrofusion process alone $(1 x$ $10^{6}$ ), or with UMR106 cells that underwent the electrofusion process alone $\left(1 \times 10^{6}\right)$, a mixture of the two $\left(1 \times 10^{6}\right)$, or UMR106 cells electrofused with Wistar DCs (dose of $1 \times 10^{6}$ ), on days 0 and 14 , and then challenged s.c. with $1 \times 10^{7}$ UMR106 cells on day 21 . Results are shown by the percentage of tumor-free rats on day 70 after tumor injection. Naive unvaccinated rats were used as a negative control in this study.

help for the development of tumor-specific CTLs. The use of tumor-allogeneic DC fusion products would be expected to have the advantage of simultaneously provision of antigen presentation, co-stimulation, and allogeneic help in the same local microenvironment. To confirm the validity of this approach, we conducted a side-by-side comparison of the antitumor response elicited by fusion products generated with syngeneic versus allogeneic DCs. In the UMR106 tumor model, immunization with fusion products generated with tumor cells and allogeneic DCs (Wistar) seemed to be superior to the prod- 


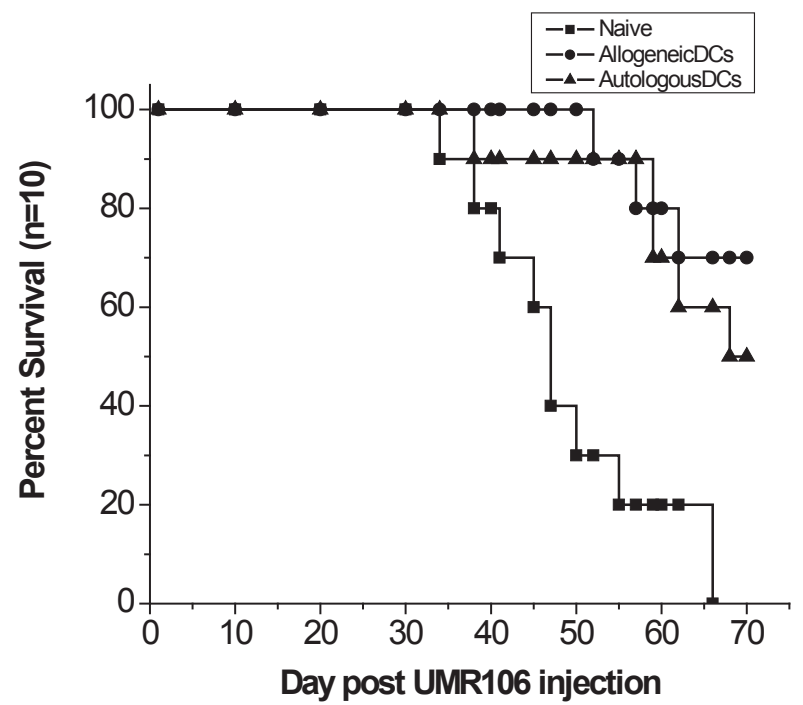

Fig. 7 Activity of electrofusion products generated with syngeneic versus allogeneic DCs. A comparison of electrofusion products generated with allogeneic versus syngeneic DCs was conducted in the UMR106 models. SD rate were immunized with the irradiated electrofusion products of UMR106 tumor cells and syngeneic SD DCs or allogeneic Wistar DCs $\left(1 \times 10^{6}\right)$ on days 0 and 14 and were then challenged s.c. with $1 \times 10^{7}$ UMR106 cells on day 21 . Naive unvaccinated rats were used as a negative control in this study. Results are shown by the percentage of the surviving rats over time after tumor challenge.

ucts generated with syngeneic DCs as assessed by the percentage of rats capable of rejecting tumor challenge, though the difference was not very obvious $(\mathrm{P}>0.05)$ (Fig. 7).

\section{Longevity of the Antitumor Response}

As described earlier, immunization with DC-tumor fusion products was found able to elicit protective activity against tumor challenge (Figs. 6 and 7). To determine whether the immunization could result in a long-term immunological memory, rats injected with UMR106allogeneic DC fusion products that survived an UMR106 tumor challenge were rechallenged with a second lethal dose of tumor cells 70 days later. A parallel group of agematched naive rats injected with UMR106 cells gradually succumbed to tumor growth. In contrast, however, all of the fusion product-immunized rats were able to reject this secondary tumor challenge, indicating that they had developed a long-term memory response (Fig. 8).

\section{Therapeutic Activity of Tumor-DC Fusion Products}

To determine whether the tumor-DC fusion vaccines could be of any use in a clinically relevant setting, the therapeutic activity of UMR106-allogeneic DC fusion products were tested in rats bearing pre-established UMR106 tumor cells. The rats were injected subcutaneously with $1 \times 10^{7}$ UMR106 cells on day 0 and were then

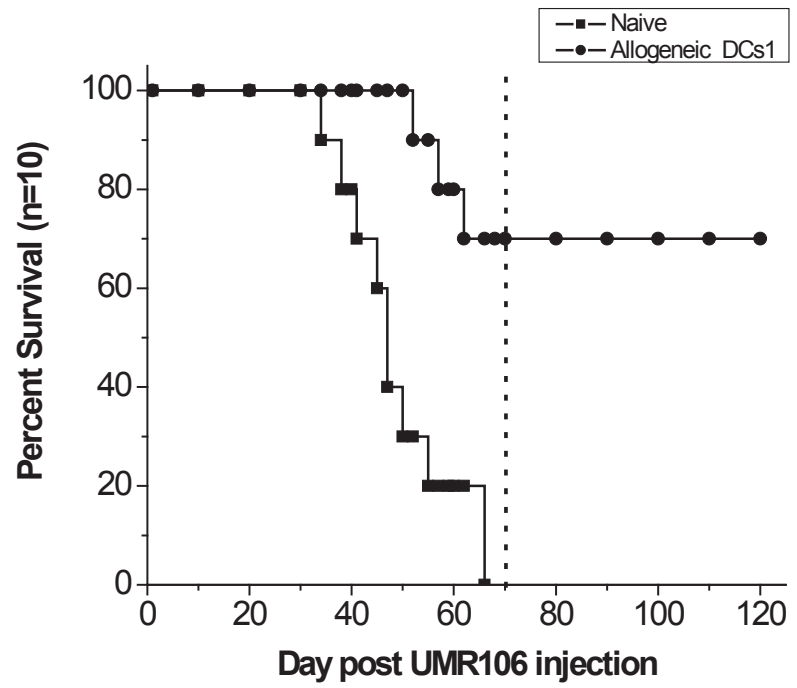

Fig. 8 Longevity of the immune response elicited by electrofusion vaccine. SD rats were immunized with the irradiated electrofusion products of UMR106 cells and allogeneic Wistar DCs $\left(1 \times 10^{6}\right)$ on days 0 and 14 and were then challenged s.c. with $1 \times 10^{7}$ UMR106 cells on day 21 . The vaccinated rats that survived the challenge $(70 \%)$ received a second s.c. injection of UMR106 cells, 7 weeks after the first challenge. All the immunized rats survived. Naive unvaccinated rats served as negative control.

treated with fusion vaccine at a dose of $1 \times 10^{6}$ or $2 \times 10^{6}$ electrofused cells on days 3, 7 and 14. The level of tumor rejection obtained was found decreased as compared with that observed in a preimmunization setting (Figs. 6 and 9). Little or no antitumor protection was observed in the rats treated with $1 \times 10^{6}$ electrofused cells $(\mathrm{P}>0.05)$, a dose sufficient to achieve substantial tumor protection in pretreatment studies. However, substantial antitumor protection (60\% long-term survivors) was obtained with a higher dose of the vaccine $\left(2 \times 10^{6}\right.$ electrofused cells $)$ $(\mathrm{P}<0.05)$. These results seemed to suggest that active treatment of tumor growth with tumor-DC electrofusion vaccines could provide a therapeutic benefit.

\section{Discussion}

The availability of an animal model to study osteosarcoma has opened several new paths for investigation. The murine and human diseases are similar in terms of pathology and, more importantly, in the interaction between the immune system and the tumor. Both human and murine osteosarcoma have low levels of MHC Class I expression, which can be upregulated by treatment with cytokines, and both are capable of eliciting some level of cellular and humoral immune reactivity. So far, the efficacy of DC-based immunotherapy for osteosarcoma has not yet been well documented. Our current work aimed 


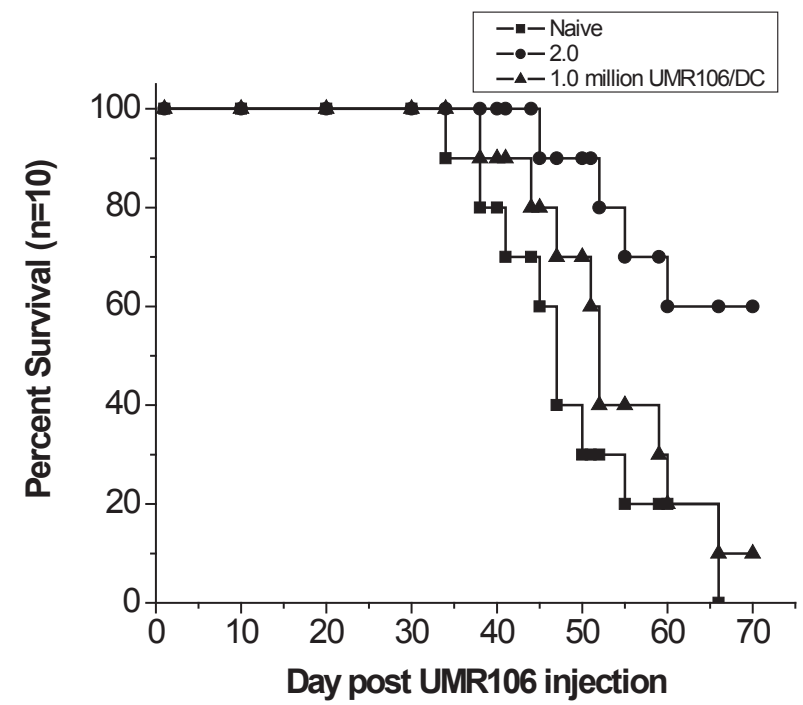

Fig. 9 Active treatment of rats bearing UMR106 tumor cells with electrofusion vaccine. SD rats were injected s.c. with $1 \times 10^{7}$ UMR106 cells on day 0 and were then treated with the irradiated electrofusion products of UMR106 tumor cells and allogeneic Wistar DCs at a dose of $1 \times 10^{6}$ or $2 \times 10^{6}$ on days 3,7 , and 14. Naive unvaccinated rats were used as negative control. Results are shown by the percentage of the surviving rats over time after tumor challenge.

to establish a rat osteosarcoma model in healthy SD rats with a normal immune system and to explore whether DC-based immunotherapy could treat osteosarcoma effectively in vivo. The results indicated that immunization with the fusion products generated by the electrofusion of allogeneic DCs and osteosarcoma cells was capable of inducing an immune response leading to tumor rejection in both pretreatment and therapeutic settings.

In immunotherapy, DC-based vaccine affords a promising new approach for the clinical response of cancers and has become an issue of the highest interest. Fused DC-tumor cells present to $\mathrm{CD} 4^{+} \mathrm{T}$-helper cells a high level to $\mathrm{T}$ cell costimulatory and MHC molecules, both of which are absent in most tumor cells. This engagement results in the upregulation of cell surface markers on T-helper cells and the secretion of various cytokines. The $\mathrm{CD}^{+} \mathrm{T}$ cell therefore provides 'help' by generating potent CTLs which are the principal effectors of specific antitumour immune responses ${ }^{20)}$. The reasoning behind the use of allogenic DCs in this study is that allogenic response would provide help for effective CTLs. However, because tumor antigens are essentially MHC molecules loaded with tumor peptides, allogenic DCs are probably providing only costimulatory signals in this approach.

Electrical cell fusion is an essential step in some of the most innovative methods in modern biology, such as the production of monoclonal antibodies, the cloning of mammals, and vaccination against cancer. Compared with the chemically induced cell fusion via polyeth- ylene glycol (PEG), electrical cell fusion is a method with higher efficiency. Technically, electrofusion is truly something interdisciplinary. To achieve success in it requires an appreciation and familiarity with both physics and electronics which is something rare among immunologists. Although simple in overall concept, the mechanism of electrofusion is still not fully understood. As a result, improvement of the methodology remains largely on an empirical basis.

One important advantage of immunization with an electrofusion product is the potential to induce an immune response against all possible tumor antigens, known or unknown. Several in vitro and in vivo applications have been explored for the use of electrofused DCtumor hybrids as $\mathrm{APCs}^{21,22)}$. The immunotherapeutic potential of these hybrid cells also has been confirmed in human clinical vaccination trials ${ }^{12,23,24)}$. Incidentally, before immunized with the rats, the fusion products of the tumor cell and the dendritic cell should be irradiated appropriately, which was to improve the therapeutical safety. After irradiation the cell survives but cannot divide so that no risks of losing control will be worried about.

In this study, the intradermal route was chosen, that was because there were some special advantages in it. The optimal number of DCs very much depends on the route and effectiveness of DCs' migration. Subcutaneous $^{25}$, intradermal ${ }^{26)}$, intravenous ${ }^{27)}$, and intranodal $^{28)}$ approaches to the delivery of DC have been respectively evaluated clinically. The intranodal approach bypasses the requirement for vaccine-loaded DC to migrate to the lymphoid tissue and simply relies on their capacity to express effective T-cell stimulative capacity. The intravenous route results in the dispersal of DC into lung, liver, spleen, and bone marrow, but not into the lymph nodes or tumour sites ${ }^{29}$. In contrast, studies using intradermal injection of bone marrow-derived DC have demonstrated direct migration of DC into the draining lymph nodes. Another DC vaccination study also has shown that $\mathrm{CD}^{+} \mathrm{T}$ cells are primed to a xenoantigen via various routes, but Th1 responses developed only after intradermal DC administration ${ }^{30)}$. And it could be speculated that the intradermal route was something predominant for this project.

UMR106 is a badly aggressive, poorly immunogenic osteosarcoma cell line, which has strong carcinogenic capability $(100 \%)$ and a high lung metastasis frequency (not lower than 70\%) according to our previous research (results not shown). However, in this study, preimmunization with the irradiated electrofusion products obtained an exciting result, that is, $70 \%$ of the treated rats lived on. Another experiment demonstrated that all of the rats that survived the primary tumor challenge were typically able to reject the second tumor challenge and remained tumor-free, indicating that they had developed a longterm memory response. 
The test to compare syngeneic dendritic cells with allogeneic ones as fusion partners showed that allogeneic vaccines were in fact just more potent and provided a little higher level of tumor protection in the UMR106 tumor model, which were not obvious statistically, though. Nevertheless, we felt satisfied with the outcome, because the option of using allogeneic DCs as a fusion partner seemed to project a practical advantage, for in a clinical setting, allogeneic DCs can be generated conveniently from stored peripheral mononuclear cells from normal healthy volunteers from the general population.

In summary, this study demonstrated it was feasible to generate a large number of DC-tumor hybrid cells by the electrofusion technique. Compared with other methods, electrofusion could be reproducible and the fusion rate tended to be high. Allogeneic DCs fused with osteosarcoma cells were capable of inducing a potent antitumor response and could be employed to treat the malignant bone tumor effectively. This approach could conceivably be applied to a wide range of cancer indications for which tumor-associated antigens have not been identified.

\section{Acknowledgments}

This work is sponsored by the National Natural Science Foundation (30330610, CHN). We would like to thank Professor Zhang Dianzhong for his technical help and Zhao Hong for his efforts in taking care of animals. We also thank Dr. Chen Xiang for his valuable advice.

\section{References}

1) Jefford, M., Maraskovsky, E., Cebon, J. and Davis, I.D. (2001). The use of dendritic cells in cancer therapy. Lancet Oncol. 2(6): 343-53. Review. Erratum in: Lancet Oncol 2001 Jul; 2(7): 455. PMID: 11905751 [PubMed - indexed for MEDLINE]

2) Kono, K., Takahashi, A., Sugai, H., Fujii, H., Choudhury, A.R., Kiessling, R. and Matsumoto, Y. (2002). Dendritic cells pulsed with HER-2/neu-derived peptides can induce specific T-cell responses in patients with gastric cancer. Clin Cancer Res. 8(11): 3394-400. PMID: 12429626 [PubMed - indexed for MEDLINE]

3) Yu, J.S., Wheeler, C.J., Zeltzer, P.M., Ying, H., Finger, D.N., Lee, P.K., Yong, W.H., Incardona. F., Thompson, R.C., Riedinger, M.S., Zhang, W., Prins, R.M. and Black, K.L. (2001). Vaccination of malignant glioma patients with peptide-pulsed dendritic cells elicits systemic cytotoxicity and intracranial T-cell infiltration. Cancer Res. 1; 61(3): 842-7. PMID: 11221866 [PubMed - indexed for MEDLINE]

4) Schaefer, B.C., Schaefer, M.L., Kappler, J.W., Marrack, P. and Kedl, R.M. (2001). Observation of antigen-dependent CD8+ T-cell/ dendritic cell interactions in vivo. Cell Immunol. 15; 214(2): 110-22. PMID: 12088410 [PubMed - indexed for MEDLINE]

5) Holtl, L., Zelle-Rieser, C., Gander, H., Papesh, C., Ramoner, R., Bartsch, G., Rogatsch, H., Barsoum, A.L., Coggin, J.H. Jr. and Thurnher, M. (2002). Immunotherapy of metastatic renal cell carcinoma with tumor lysate-pulsed autologous dendritic cells. Clin Cancer Res. 8(11): 3369-76. PMID: 12429623 [PubMed - indexed for MEDLINE]

6) Labarriere, N., Bretaudeau, L., Gervois, N., Bodinier, M., Bougras, G., Diez, E., Lang, F., Gregoire, M. and Jotereau, F. (2002). Apoptotic body-loaded dendritic cells efficiently cross-prime cytotoxic T lymphocytes specific for NA17-A antigen but not for Melan-A/MART-1 antigen. Int J Cancer. Sep 20; 101(3): 280-6. PMID: 12209980 [PubMed - indexed for MEDLINE]

7) Frolkis, M., Fischer, M.B., Wang, Z., Lebkowski, J.S., Chiu, C.P. and Majumdar, A.S. (2003). Dendritic cells reconstituted with human telomerase gene induce potent cytotoxic T-cell response against different types of tumors. Cancer Gene Ther. 10(3): 239-49. PMID: 12637945 [PubMed - indexed for MEDLINE]

8) Miller, P.W., Sharma, S., Stolina, M., Butterfield, L.H., Luo, J., Lin, Y., Dohadwala, M., Batra, R.K., Wu, L., Economou, J.S. and Dubinett, S.M. (2000). Intratumoral administration of adenoviral interleukin 7 gene-modified dendritic cells augments specific antitumor immunity and achieves tumor eradication. Hum Gene Ther. 11(1): 53-65. PMID: 10646639 [PubMed - indexed for MEDLINE]

9) Schuler-Thurner, B., Dieckmann, D., Keikavoussi, P., Bender, A., Maczek, C., Jonuleit, H., Roder, C., Haendle, I., Leisgang, W., Dunbar, R., Cerundolo, V., von Den Driesch, P., Knop, J., Brocker, E.B., Enk, A., Kampgen, E. and Schuler, G. (2000). Mage-3 and influenza-matrix peptide-specific cytotoxic $\mathrm{T}$ cells are inducible in terminal stage HLA-A2.1+ melanoma patients by mature monocyte-derived dendritic cells. J Immunol. 165(6): 3492-6. PMID: 10975870 [PubMed - indexed for MEDLINE]

10) Rains, N., Cannan, R.J., Chen, W. and Stubbs, R.S. (2001). Development of a dendritic cell (DC)-based vaccine for patients with advanced colorectal cancer. Hepatogastroenterology. 48(38): 347-51. PMID: 11379307 [PubMed - indexed for MEDLINE]

11) Heiser, A., Coleman, D., Dannull, J., Yancey, D., Maurice, M.A., Lallas, C.D., Dahm, P., Niedzwiecki, D., Gilboa, E. and Vieweg, J. (2002). Autologous dendritic cells transfected with prostatespecific antigen RNA stimulate CTL responses against metastatic prostate tumors. J Clin Invest. 109(3): 409-17. PMID: 11828001 [PubMed - indexed for MEDLINE]

12) Gong, J., Nikrui, N., Chen, D., Koido, S., Wu, Z., Tanaka, Y., Cannistra, S., Avigan, D. and Kufe, D. (2000). Fusions of human ovarian carcinoma cells with autologous or allogeneic dendritic cells induce antitumor immunity. J Immunol. 165(3): 1705-11. PMID: 10903782 [PubMed - indexed for MEDLINE]

13) Gong, J., Avigan, D., Chen, D., Wu, Z., Koido, S., Kashiwaba, M. and Kufe, D. (2000). Activation of antitumor cytotoxic T lymphocytes by fusions of human dendritic cells and breast carcinoma cells. Proc Natl Acad Sci USA. 97(6): 2715-8. Erratum in: Proc Natl Acad Sci USA 2000 Apr 25; 97(9):5011. PMID: 10688917 [PubMed - indexed for MEDLINE]

14) Tanaka, H., Shimizu, K., Hayashi, T. and Shu, S. (2002). Therapeutic immune response induced by electrofusion of dendritic and tumor cells. Cell Immunol. 220(1): 1-12. PMID: 12718934 [PubMed - indexed for MEDLINE]

15) Karsten, U., Stolley, P., Walther, I., Papsdorf, G., Weber, S., Conrad, K., Pasternak, L. and Kopp, J. (1988). Direct comparison of electric field-mediated and PEG-mediated cell fusion for the generation of antibody producing hybridomas. Hybridoma. 7(6): 627-33. PMID: 3235098 [PubMed - indexed for MEDLINE]

16) Zimmermann, U., Vienken, J., Halfmann, J. and Emeis, C.C. (1985). Electrofusion: a novel hybridization technique. Adv Biotechnol Processes. 4: 79-150. Review. No abstract available. PMID: 3902055 [PubMed - indexed for MEDLINE]

17) Fan, Q.Y., Ma, B.A., Zhou, Y., Zhang, M.H. and Hao, X.B. (2003). Bone tumors of the extremities or pelvis treated by microwave-induced hyperthermia. Clin Orthop. (406): 165-75. PMID: 12579016 [PubMed - indexed for MEDLINE]

18) Lee, W.C., Wang, H.C., Jeng, L.B., Chiang, Y.J., Lia, C.R., Huang, P.F., Chen, M.F., Qian, S. and Lu, L. (2001). Effective treatment of small murine hepatocellular carcinoma by dendritic cells. Hepatology. 34(5): 896-905. PMID: 11679960 [PubMed - indexed for MEDLINE]

19) Barratt-Boyes, S.M., Zimmer, M.I., Harshyne, L.A., Meyer, E.M., Watkins, S.C., Capuano, S. 3rd, Murphey-Corb, M., Falo, L.D. Jr. and Donnenberg, A.D. (2000). Maturation and trafficking of monocyte-derived dendritic cells in monkeys: implications for dendritic cell-based vaccines. J Immunol. 164(5): 2487-95. PMID: 10679086 [PubMed - indexed for MEDLINE]

20) Roth, C., Rochlitz, C. and Kourilsky, P. (1994). Immune response against tumors. Adv Immunol. 57: 281-351. Review. No abstract available. PMID: 7872159 [PubMed - indexed for MEDLINE]

21) Siders, W.M., Vergilis, K.L., Johnson, C., Shields, J. and Kaplan, 
J.M. (2003). Induction of specific antitumor immunity in the mouse with the electrofusion product of tumor cells and dendritic cells. Mol Ther. 7(4): 498-505. PMID: 12727113 [PubMed - indexed for MEDLINE]

22) Orentas, R.J., Schauer, D., Bin, Q. and Johnson, B.D. (2001). Electrofusion of a weakly immunogenic neuroblastoma with dendritic cells produces a tumor vaccine. Cell Immunol. 213(1): 4-13. PMID: 11747351 [PubMed - indexed for MEDLINE]

23) Kugler, A., Stuhler, G., Walden, P., Zoller, G., Zobywalski, A., Brossart, P., Trefzer, U., Ullrich, S., Muller, C.A., Becker, V., Gross, A.J., Hemmerlein, B., Kanz, L., Muller, G.A. and Ringert, R.H. (2000). Regression of human metastatic renal cell carcinoma after vaccination with tumor cell-dendritic cell hybrids. Nat Med. 6(3): 332-6. PMID: 10700237 [PubMed - indexed for MEDLINE]

24) Parkhurst, M.R., DePan, C., Riley, J.P., Rosenberg, S.A. and Shu, S. (2003). Hybrids of dendritic cells and tumor cells generated by electrofusion simultaneously present immunodominant epitopes from multiple human tumor-associated antigens in the context of MHC class I and class II molecules. J Immunol. 170(10): 5317-25. PMID: 12734382 [PubMed - indexed for MEDLINE]

25) Schuler-Thurner, B., Schultz, E.S., Berger, T.G., Weinlich, G., Ebner, S., Woerl, P., Bender, A., Feuerstein, B., Fritsch, P.O., Romani, N., Schuler and G. (2002). Rapid induction of tumorspecific type $1 \mathrm{~T}$ helper cells in metastatic melanoma patients by vaccination with mature, cryopreserved, peptide-loaded monocytederived dendritic cells. J Exp Med. 195(10): 1279-88. Erratum in: J Exp Med. 2003 Feb 3; 197(3): 395. PMID: 12021308 [PubMed indexed for MEDLINE]
26) Thurner, B., Haendle, I., Roder, C., Dieckmann, D., Keikavoussi, P., Jonuleit, H., Bender, A., Maczek, C., Schreiner, D., von den Driesch, P., Brocker, E.B., Steinman, R.M., Enk, A., Kampgen, E. and Schuler, G. (1999). Vaccination with mage-3A1 peptidepulsed mature, monocyte-derived dendritic cells expands specific cytotoxic $\mathrm{T}$ cells and induces regression of some metastases in advanced stage IV melanoma. J Exp Med. 190(11): 1669-78. PMID: 10587357 [PubMed - indexed for MEDLINE]

27) Fong, L., Hou, Y., Rivas, A., Benike, C., Yuen, A., Fisher, G.A., Davis, M.M. and Engleman, E.G. (2001). Altered peptide ligand vaccination with Flt3 ligand expanded dendritic cells for tumor immunotherapy. Proc Natl Acad Sci USA. 98(15): 8809-14. Epub 2001 Jun 26. PMID: 11427731 [PubMed - indexed for MEDLINE]

28) Jonuleit, H., Giesecke-Tuettenberg, A., Tuting, T., Thurner-Schuler, B., Stuge, T.B., Paragnik, L., Kandemir, A., Lee, P.P., Schuler, G., Knop, J. and Enk, A.H. (2001). A comparison of two types of dendritic cell as adjuvants for the induction of melanoma-specific T-cell responses in humans following intranodal injection. Int $\mathbf{J}$ Cancer. 93(2): 243-51. PMID: 11410873 [PubMed - indexed for MEDLINE]

29) Morse, M.A., Coleman, R.E., Akabani, G., Niehaus, N., Coleman, D. and Lyerly, H.K. (1999). Migration of human dendritic cells after injection in patients with metastatic malignancies. Cancer Res. 59(1): 56-8. PMID: 9892184 [PubMed - indexed for MEDLINE]

30) Fong, L., Brockstedt, D., Benike, C., Wu, L. and Engleman, E.G. (2001). Dendritic cells injected via different routes induce immunity in cancer patients. J Immunol. 166(6): 4254-9. PMID: 11238679 [PubMed - indexed for MEDLINE] 